\title{
LOS CUESTIONAMIENTOS ÉTICOS DE FREUD: PSICOANÁLISIS, EXISTENCIA Y MUERTE
}

\author{
Gustavo Figueroa ${ }^{1}$
}

Resumen: Freud no criticó los fundamentos de la ética ni prescribió deberes, prohibiciones, aspiraciones o respuestas alternativas a problemas tradicionales, sino entregó una nueva manera de formular problemas morales. Existen tres áreas en que Freud insinuó una ética que sostiene una dirección diferente a la actual bioética.1. El carácter no ético del psicoanálisis no está incluido entre las técnicas de dominación o adoctrinamiento sino en las de veracidad, en lo que importa es el auto-reconocimiento, la mala comprensión es la ruta necesaria para la comprensión. 2. La postura final de Freud mismo hacia su propia muerte se puede llamar apropiación de su finitud, cuando él asumió su ser-referido-a-la-muerte, no como estar-en-su-final, indicando con ello que comprendió que el final siempre penetró en su vida. 3. En la auténtica comprensión de sí mismo, Freud entendió que la última potencialidad de su existencia fue abandonarse a sí, reveló su potencialidad para su no-potencialidad, haciéndose libre para su propio fin, aceptó su existencia en su finitud.

Palabras clave: existencia, ética, autenticidad, ser-en-el-mundo, mortalidad, culpa.

\section{Freud's ethical quandaries: psychoanalysis, existence and death}

\begin{abstract}
Freud did not make a critique of foundations of ethics nor prescribed duties, prohibitions, aspirations or alternative answers to unchanged questions, but he gave a new manner of asking moral questions. There are three areas in which Freud implied an ethic that maintains a different direction from current bioethics.1. The fundamentally nonethical character of Freud's psychoanalysis is not included in the techniques of domination or indoctrination but of veracity, what is at stake is selfrecognition, misunderstanding is the necessary path to understanding. 2 . The final position of Freud himself to his own death can be called appropriation of his finitude, when he assumed his being-unto-death, not as a being-at-his-end, indicating thereby that he understood that the end always penetrated his whole existence. 3. In the authentic comprehension of his self, Freud understood that the ultimate potentiality of his existence was to relinquish his self, he revealed to his self his potentiality for non-potentiality, becoming free for his own end, he accepted his existence in its finitude.
\end{abstract}

Key words: existence, ethics, authenticity, being-in-the-world, mortality, fault

\section{Os questionamentos éticos de Freud: psicanálise, existência e morte}

Resumo: Freud não criticou os fundamentos da ética nem prescreveu deveres, proibiçóes, aspiraçóes ou respostas alternativas a problemas tradicionais, e sim apresentou uma nova maneira de formular problemas morais. Existem três áreas nas quais Freud insinuou uma ética que indica uma direção diferente da atual bioética. 1 . O caráter não ético da psicanálise não está incluído entre as técnicas de dominação ou doutrinamento e sim nas de veracidade, onde o que importa é o auto-reconhecimento, a má compreensão é o caminho necessário para a compreensão. 2. A postura final de Freud, mesmo até sua morte, pode se chamar de "apropriaçáo de sua finitude", quando ele assumiu seu ser-referido-à- morte, não como estar-em-seu-final, indicando com isto que compreendeu que o final sempre infiltrou sua vida. 3. Na autêntica compreensão de si mesmo, Freud entendeu que a última potencialidade de sua existência foi abandonar-se a si, revelou sua potencialidade para sua não-potencialidade, libertando-se para seu próprio fim, aceitou sua existência em sua finitude.

Palavras chave: existência, ética, autenticidade, ser-no-mundo, mortalidade, culpa

\footnotetext{
${ }^{1}$ Departamento de Psiquiatría, Escuela de Medicina, Universidad de Valparaíso, Chile Correspondencia: gfigueroacave@gmail.com
} 


\section{Modi res considerandi}

La ética médica cumplirá un cuarto de siglo(1), lapso en que desencadenó una revolución insospechada que ha remecido principios fundamentales, no solo de la medicina sino, asimismo, de las ciencias biológicas, filosofía, teología, sociología, derecho, política $(2,3)$. A lo largo de su historia, la medicina había sido sustentada éticamente, de modo inequívoco, por el Juramento hipocrático, profundizado sucesivamente por desarrollos, transformaciones y mutaciones $(4,5)$. Sorprende la carencia de hipótesis suficientemente iluminadoras para entender a cabalidad la génesis de esta conmoción tan imprevista como estremecedora de sus bases(6). Se han postulado factores provenientes de la ética (argumentaciones con la convicción íntima de nunca poder llegar a acuerdo) (7), históricos (desencantamiento, disolución de valores), médicos (pragmatic turn, medicina basada en la evidencia) y jurídicos (litigios ante tribunales) (biolaw) (8) como significativos, aunque no decisivos en el vuelco(9).

Quizás teniendo presente la máxima de Descartes, que para saber los principios de las personas exige fijarse "más bien en lo que hacen que en lo que dicen"(10), Nietzsche invirtió el dilema: la moral nunca fue problema para el pensar, más bien "fue aquello en donde, luego de toda desconfianza, discordia, contradicción, se llegaba a un acuerdo entre todos, el sagrado lugar de la paz, donde los pensamientos descansaban de sí mismos"(11). La moral ha sido maestra en todas las acciones diabólicas del arte de persuadir, así como Circe, hechicera mitológica que, para retener a Odiseo, transformó en cerdos a sus osados compañeros. "Desde siempre, desde el tiempo en que se habla y se persuade en la tierra, la moral, precisamente, se ha manifestado como la mayor maestra de la seducción $-\mathrm{y}$, en cuanto a nosotros (...) como la verdadera Circe (...)"(12). Vale decir, cual Circe, la moral cautivó también a los médicos, siempre atareados en enfrentarse con problemas de vida y muerte, con teorías que, aunque atractivas, resultaron inoperantes para resolverlos en la actualidad. De ahi que se tornó imprescindible desoir sus cantos de sirena y acudir a principios diferentes a los que sostenía la ética médica tradicional y elaborar una bio-ética destinada a enfrentar el nuevo desafío irrenuncia- ble: todo acto médico es un acto moral(13).

Empero, surgen dos cuestiones: el procedimentalismo y guías específicas(14), ¿están objetivando, calculando y estandarizando la moral médica, por tanto, aplicando el pensar técnico propio de la modernidad?(15). Y la segunda, y corolario de la anterior, ¿está la bioética suficientemente fundada en sus bases, como para asegurar que salvó no solo a la ética sino también y especialmente a la medicina, proporcionándole una perspectiva original, novedosa, inédita?(16).

Freud puede ayudar en las cuestiones que acucian a la bioética, a pesar de sus fuertes declaraciones: "el postulado de que la ciencia debería elaborar una ética es injusto - la ética es una especie de regulación de tránsito para el trato entre los hombres"; "a mí la ética me es extraña..., no me quiebro mucho la cabeza en relación con el bien y el mal..., si hay que hablar de ética, reconozco un bien elevado"; y termina con su sorprendente aseveración: un psicoanalista "necesita volverse un mal sujeto, transformarse, renunciar, comportarse como un artista que compra pinturas con el dinero del gasto de su mujer (...), sin un poco de esa calidad de malhechor no se obtiene un resultado correcto"(17). Pero Freud solía relatar a su hija Anna una historia que revela, embozada, oblicuamente, el complejo problema de la vida, la muerte y la ética que le apremiaba existencialmente: "Vivía en Persia un hombre que, un día, yendo por la calle, vio del otro lado de la misma a la muerte. La muerte le hizo señas. Ello lo aterrorizó. Corrió hacia lo de un amigo y le pidió: "Préstame tu más veloz caballo para que pueda cabalgar hasta Isfahan y allí esconderme. Hoy encontré a la muerte por la calle, me hizo señas, y ello debe de haber significado que venía a buscarme. Tal vez pueda escapar de ella". Cabalgó hasta Isfahán. Al atardecer, la muerte fue allá a buscarlo. Él se asustó profundamente y dijo: "Pensé que habría podido escapar de ti. ¿Por qué me hiciste señas hoy?”. Y la muerte respondió: "No te hice señas. Fue un gesto de sorpresa, ya que había recibido la orden de ir a buscarte esta noche a Isfahan, y tú estabas por la mañana tan lejos de ese lugar"(18). La penetrante y compleja postura de Freud ante el sentido moral último esencial a la vida humana plantea tres dilemas a la bioética: el contenido ético inherente al psicoa- 
nálisis, la apropiación de su morir y la responsabilidad de su existir.

\section{La ética del psicoanálisis}

$\mathrm{Al}$ inicio de sus investigaciones, un hallazgo sorprendió a Freud por lo inesperado, según escribió a su amigo Flieb, donde vaticina el sentido profundo del mito griego de Edipo: "Otro presentimiento me dice, como si ya lo supiera - aunque en verdad yo no sé nada en absoluto- que estoy por descubrir la fuente de la moralidad" (19). Sin embargo, no se interesó en elaborar valores y reglas de acción para ser exigidas por distintos organismos prescriptivos, esto es, la responsabilidad médica no se soluciona tan solo acudiendo a las leyes y normas jurídicas obligatorias para todos. Tampoco con un "pedir cuentas" o "rendir cuentas" del sujeto ante los demás, so pena de caer bajo el peso de la ley, esto es, evaluar el comportamiento real de los individuos en relación con códigos y reglamentos 3/4bioética de "mínimos"(20). En Freud se lleva a cabo un giro del cuestionamiento: él procura entender la posibilidad de lo ético formulando preguntas diferentes a las tradicionales; al no entregar respuestas alternativas a dilemas históricamente instituidos, busca contrariamente elaborar una nueva manera de interrogar(21).

Freud enfatizó la necesidad de cumplir dos requisitos por parte del paciente antes de iniciar el tratamiento. Como "condiciones de la cura" advirtió, por un lado, que "no olvide usted nunca que ha prometido ser absolutamente sincero (Aufrichtigkeit) y no calle nunca algo porque le resulte desagradable comunicarlo"(22), con lo cual ubicó todo el proceso bajo una alta exigencia de honestidad, que sirve de trasfondo insoslayable y compromete a ambos por igual. Empero, no se trata de sancionar pensamientos, deseos o conductas reales o imaginadas, sino de fijar el marco que hace posible un encuentro interpersonal —inédito en la vida cotidiana—, esto es, sinceridad, sin constreñir la autonomía de los participantes. Al agregar Freud "nos negamos enfáticamente a... forzarlo a aceptar nuestros ideales" (23), robustece que suspende toda valoración moral, de modo tal que los juicios éticos no determinen, condicionen, encubran o tiñan el encuentro paciente-terapeuta.
Por otra parte, que el proceso se circunscribirá al habla, al intercambio a través del diálogo, a una curación por la palabra(24). La pragmática analítica ha señalado que hablar se comprende como emitir actos locucionarios o ejecutivos: pronunciar frases correctas gramaticalmente cuyo contenido tiene sentido, "el acto de decir algo". De ahí que se mueven en el plano verdad/falsedad (truth values), verificables en la realidad, utilizando procedimientos objetivos y empíricos(25). Empero, en una psicoterapia concurren actos ilocucionarios: con idénticas palabras, es posible "interrogar", "seducir", "retar", "aconsejar", "controlar", etc.; lo que sucede es que al acto locucionario le es inherente, en cada oportunidad, poseer una fuerza ilocucionaria precisa: la fuerza de una orden, de una amonestación, etc. La situación y el contexto precisan si lo dicho es, no verdadero ni falso, sino afortunado o desafortunado (infelicities), si funciona o no está en orden(26). Además, el hablar es un acto perlocucionario: genera efectos en el otro mientras interroga o inquiere..., tal como saberse culpable, sentirse exitado, experimentarse apoyado, necesitado de consuelo, cambiar de opinión, etc.(27). Vale decir, Freud transforma la psicoterapia de "ideas que se emiten" (27) en "decir como acción", —en actoscuya misión no es formular pensamientos comprensibles, sino producir efectos; es un quehacer, una praxis destinada, por una parte, a poseer un meta (fuerza ilocucionaria), y, por otro, a no afanarse por la verdad verificable y abstracta, o por entregar datos comprobables, sino provocar el orden, esclarecimiento, la adecuación no convencional, aunque no siempre se consiga(28): es la nueva versión del "bello discurso" (lógos kalós) de Platón, para producir sophrosyne en el alma, una ordenación bella, armoniosa y justa(29).

Por ello, para Freud, la psicoterapia es un trabajo (Arbeit), una tecnología no solo racional-teleológica —instrumental o estratégica- destinada hacia una meta, que escoge medios y estima consecuencias de la naturaleza, orgánica o de funciones psicológicas, sino especialmente una tecnología comunicativa o simbólicamente mediada, enfocada a reorganizar los fines según nuevas definiciones o sentidos de la situación(30). Eso significa que obedece a ciertos intereses, como toda ciencia, según Habermas, pero no 
a un interés de manipulación sino a un interés práctico de comprender el sentido y sobre todo a un interés emancipatorio por encaminar a la liberación(31). Pero, además, es una tecnología del yo, que propende a "un cierto desciframiento de uno mismo", vale decir, a un "cierto número de operaciones en el propio cuerpo, en el alma, en los pensamientos, en la conducta, de modo tal que se transforma a sí mismo"(32): se ocupa del sí (soi, self), se redescubre éste a sí, se modifica, se reconstruye a sí mismo. Foucault refirió "el ocuparse de uno mismo" (epimeleia heatou, cura sui) a la tradición de "la reflexión acerca de los modos de vida, las elecciones de existencia, la manera de regular su conducta y de fijarse uno mismo fines y medios"(33). Por tanto, esta preocupación de sí o inquietud por sí va más allá del "conócete a ti mismo" (gnothi sauton) del oráculo de Delfos y Sócrates(34), puesto que "uno mismo" no es un objeto enteramente dado, una sustancia primera que, antes que cualquier otra cosa, es posible "conocer"(35); como decía Nietzsche, no es un origen (Ursprung), sino una emergencia (Entstehung) (36,37). Para Freud, la psicoterapia es más que un conocer o saber, es un conjunto de actos o prácticas que posibilitan, a través del otro, el objetivo no de descubrir, sino de rechazar lo que se es, de aprehender las contradictorias configuraciones históricas que se han ido generando durante la existencia.

La ética del psicoanálisis se gesta cuando Freud comprende —en su autoanálisis(38)— que el destino de Edipo es "ya" haber asesinado a su padre y "ya" haberse casado con su madre(39). Pero el drama consiste en el reconocimiento de sí y este surge más allá de este punto; reconocerse es admitir, asumir y apoderarse de ser el hombre que él mismo había anteriormente maldecido: "Yo soy ese hombre. En un cierto sentido, siempre lo he sabido, pero en otro sentido no; ahora sé quien soy" (40-42). En lugar de moralizar sobre este doble crimen, Freud da una vuelta de tuerca e inquiere por qué este desenmascaramiento es posible de llevar a cabo o, lo que es igual, cómo sucede que nos comprendamos mal -insinceramente, oblicuamente- en forma regular, habitual e inadvertida, por qué se oculta a la vez otro sentido por detrás del distorsionado.

El mostrar-ocultar ha sido uno de los grandes géneros que ha ocupado al pensar desde los tiempos de Platón(43), cuestión que puso en jaque al dictum de Descartes, al plantear el doble sentido: se tiene una certeza inmediata de sí-mismo, pero esta certidumbre no es un conocimiento evidente, irrefutable, apodíctico. Husserl señaló que la conciencia (Bewußtsein) es "intencional" —está destinada a algo que ella, como conciencia, no es, sino al sentido de lo aludido o designado(44). Por ello, hay que diferenciar: "ser consciente" es saberse con certeza incontrovertible, pero "lo que" se conoce no es como uno cree de modo inmediato. Es necesario efectuar un giro: el conocimiento de sí no se encuentra al inicio sino al final de una exploración, ardua, trabajosa, concienzuda y a veces sin término; en otras palabras, la conciencia no es origen (Ursprung) sino tarea (Arbeit) (45). Freud lo vio claro al denominar esta búsqueda "interpretación (Auslegung) de la vida del paciente (y del terapeuta)": la interpretación es la inteligencia del doble sentido(46).

En otras palabras, Freud lleva a cabo una triple neutralización o puesta entre paréntesis de la "realidad": de los datos referidos por el paciente, de los principios y valores morales vigentes y de las conductas y actos éticos realizados en las interacciones del enfermo. Las "condiciones de la cura" posibilitan apuntar a los mecanismos de distorsión, disfraces, falsificaciones, ilusiones; por tanto, a asumir las simulaciones e insinceridades que están a la base del paciente. Su autocomprensión progresiva es una herida narcisística que se profundiza a medida que avanza el tratamiento, lo que significa que el psicoanálisis es una técnica que tiene como único valor ético la veracidad, en contraposición a las técnicas de la dominación y a las técnicas de adoctrinamiento — técnica que implica reconocerse en los fraudes, disimulos, ficciones que constituyen al paciente- La veracidad consigo es un proceso íntimo, intransferible, inagotable. Lo que sucede es que Freud está emparentado con el coro de Agamenón de Esquilo: pathei-mathos, "la sabiduría [sinceridad] sólo se alcanza a través del sufrimiento"(47). Es preciso des-legitimar la ética médica — suspenderla - para revindicarla gracias a la veracidad.

\section{La apropiación ética del morir de Freud}

La enfermedad de Freud, que lo condujo a su 
muerte, presentó problemas éticos profundos, variados, contradictorios, humanos, que acaecieron antes del nacimiento de la bioética, quizás avizorándola, y que se pueden dividir en dos periodos, de acuerdo con los dilemas centrales.

1) La comunicación del diagnóstico. El 7 de abril de 1923, el doctor Félix Deutsch, su Leibartz, acude a la casa de Freud para examinar su cavidad bucal a causa de una tumoración. Deutsch se impactó: "a la primera mirada no tuve dudas que se trataba de un cáncer avanzado. Para tomarme tiempo, realicé un segundo examen y decidí llamarlo "un mal caso de leucoplasia..." (48). Su desazón aumentó cuando Freud le conminó a que "lo ayudara a abandonar este mundo en actitud digna (mit Anstand), si estaba condenado a morir en medio del sufrimiento, y le habló de lo difícil que le sería a su madre sobrellevar la muerte de su hijo". El encuentro culminó cuando Freud comprometió solemnemente a Deutsch a que le notificara la verdad del resultado de la biopsia y selló el encuentro estrechándole la mano, como signo de este juramento(49) (ver tabla I).

La situación continuó en una atmósfera poco clara: Deutsch insinuándole que se trataba de una masa posiblemente benigna. Freud es operado de la mandíbula, en un cruento procedimiento, por el Dr. Markus Hajek quien, de manera ambigua, tampoco formuló su impresión diagnóstica y recomendó radioterapia. Deutsch siguió visitándolo sin hablar del tumor, porque "Freud no estaba suficientemente preparado para enfrentar una realidad como él la veía” y continuó temiendo lo que le pareció percibir desde el primer encuentro: la posibilidad de que él se suicidara.

Asimismo, la familia no fue puesta en conocimiento del hallazgo y, como era habitual, emprendieron juntos sus vacaciones de junio hacia los Alpes. Un sangramiento le hace pedir ayuda a Hajek, pero este tarda 15 días en responder: "no es necesario que vuelva a verlo" por el momento. Angustiado, Freud acude a Deutsch, que descubre la reincidencia de la masa tumoral, situación de notoria urgencia y delicada evaluación. No comunica el hallazgo ni a Freud ni a su familia, sino decide debatirlo al interior del "Comité", círculo de trabajo de amigos personales de Freud, que se halla reunido en las cercanías, sesionando sobre el futuro del movimiento psicoanalítico(50). La noticia los sobrecoge como un cataclismo aterrador, pero se resuelve no informar aún a Freud, ya que éste añora un viaje a Roma con su hija Anna; de hecho, el anhelado viaje a Italia rebasó todas las ilusiones de padre e hija.

Una hemorragia masiva sobresalta a los viajeros $y$, tras su apresurado regreso, Deutsch se contacta con el Dr. Hans Pichler, nuevo cirujano. El diagnóstico de "leucoplasia proliferativa papilar en el arco palatino derecho anterior" es comunicado a Freud, aunque se desconoce quién pronunció el diagnóstico de cáncer. Tras la resección del maxilar superior derecho, paladar derecho y parte de la mandíbula, previo vaciamiento ganglionar, comienza una interminable odisea de operaciones y confecciones de prótesis hasta el final de su vida, con incremento ininterrumpido de molestias, dolores, infecciones, dificultades del habla, audición e incapacidad para comer(51).

Lo acaecido quebranta los cimientos de la relación Freud-Deutsch. Freud manifiesta que la pérdida absoluta de confianza imposibilita que éste permanezca como su médico personal y le enrostra en numerosas misivas las faltas cometidas, especialmente, haber retenido el diagnóstico (posteriormente se indignó que se hubiera consultado al "Comité" sin su consentimiento)(52). Por su parte, Deutsch justificó parte de sus notwendigen Notlügen (mentiras piadosas necesarias) con la esperanza que él tenía de que la cirugía sustraería con éxito todo el tumor y "con un poco de suerte, Ud. no lo habría sabido nunca” (53); sustentó el viaje a Roma, porque "yo sabía que 2 o 3 semanas no producirían un cambio decisivo" en el avance de la neoplasia; además, consultó a Pichler, quien apoyó la medida de la excursión. Empero, Deutsch asumió ser el único responsable de la "traición", como él mismo la catalogó, aunque en cartas a su esposa le manifiesta sus sentimientos hacia el maestro: "Su yo no ha demostrado durante su enfermedad ser tan digno de amor ni tan fuerte como le gustaría afirmar. Y ahora, cuando se está recuperando, profundamente herido, sólo puede cumplir la tarea de restauración del yo en medio de una gran lesión orgánica que no desaparece, retirando la libido de quien fue testigo de su debilidad. Intenta racionalizar su inaccesibilidad con el argumento de 
la incertidumbre de su enfermedad. Tiene que culpar a alguien" $(54,55)$.

El proceder ético de la interacción entre Freud y Deutsch, antes de la introducción de la bioética, se entiende a partir de cada participante. 1] $\mathrm{La}$ ética de Deutsch. a] El fin moral que él procura son los mejores intereses de Freud como persona, según los entiende la ciencia médica. Ambos, como médicos, conocían del privilegio terapéutico, la autoridad científica trasciende criterios y creencias particulares al saber fácticamente lo mejor para el paciente: experiencia clínica, sabiduría terapéutica. b] El valor primario de la medicina es el cuidado de la salud, de ahí que Deutsch se esfuerza sin dudarlo por proporcionar cuidado, ad-sistencia, bienestar a Freud; por ello, toma decisiones, asume la dirección, resuelve desde sí mismo la ruta que ha de seguir todo el proceso terapéutico. c] Primun non nocere del "Juramento"4: no dañar a Freud, física o espiritualmente, aunque éste tuviera las mejores razones e intenciones para exigir sus privilegios; la posibilidad de un desenlace infausto, cuando menos nocivo, en caso de que Freud conociera su dolencia, puso a Deutsch ante la imperiosidad de guardar para sí el fatídico pronóstico. d] La prudencia o phrónesis: el más hábil empleo de la técnica según él la había aprendido anteriormente en su vida profesional. e] Evitación de cualquier hybris, desmesura, temeridad o desenfreno por parte de su persona. 2. La ética de Freud. a] Él tenía el derecho a conocer toda la verdad, a afrontar a la ananké - los rigores y mandatos del ineludible destino que impone, doblega, somete- - b] Decidir y determinarse según sus valores propios, esto es, siguiendo su interna necesidad, en acuerdo a sus creencias sobre la vida que él quería realizar, aunque este proyecto de vida no fuera del todo compartido por la ciencia médica. c] Freud censuró la paradoja: Deutsch silenció ex profeso el diagnóstico porque sabía precisamente que estaba capacitado y en situación de sacar conclusiones de carácter médico y personal de los datos; como hombre adulto responsable, amén de médico, podía aclarar sus dilemas de salud y existencia. d] Freud entendió que Deutsch no lo agredió (battery), aunque le reprochó que le infligió un daño severo por omisión (malpractice), menoscabó no solo su libertad, sino especialmen- te su dignidad. e] Deutsch conocía a cabalidad los valores personales de Freud manifestados por éste en innumerables ocasiones durante su relación con él, por ello, no correspondían al arbitrio del infausto momento ni se comprendían a partir de caprichos del carácter(56). Además, acababa de aparecer en un libro de Freud que Deutsch conocía de seguro: "Si uno está destinado a morir..., preferiría estar sometido a una ley natural incontrastable, la sublime ananké (necesidad), y no a una contingencia que tal vez habría podido evitarse. Pero esta creencia en la legalidad interna del morir acaso no sea sino una de las ilusiones que hemos engendrado para "soportar la carga de la existencia..."(57). f] Para Freud, la moral de la interacción terapeuta-paciente no se basa tanto en ser-verdadera (being-truth) — estar enfermocomo en una ética fundada en decir-la-verdad (saying-truth) - llegar a autoconocerse y asumirse enfermo-(58), proclamar la verdad-de-sí se daba en el ámbito de la comunicación interpersonal. 3. Las incógnitas de la ética de la interacción. Muchas interrogantes quedan sin resolver, lo que significa que la ética del morir presenta muchas facetas más allá de las tradicionales. Por qué: a] ¿Freud no comunicó su condición a sus familiares? b] ¿Freud no sospechó de su afección cuando fue sometido a radioterapia? c] ¿̨no se informó a los parientes? d] ¿Anna no preguntó a los integrantes del "Comité", ya que ella estuvo al final de la reunión? e] ¿Markus Hajek no acudió a petición de Freud con ocasión de su hemorragia? f] ¿sus discípulos se arrogaron el privilegio de decidir por él?

2) El proceso del morir de Freud. Desde finales de 1928 Freud sustituirá su médico de cabecera y escogerá las siguientes palabras para aclarar su relación con Max Schur: "Algunas desafortunadas experiencias con sus predecesores" le obligaban a exigir que se le dijera la verdad sobre su condición, cualquiera fuera esta. Al aceptar Schur este contrato, Freud terminó con "Prométame algo más: que cuando llegue el momento no me hará sufrir innecesariamente". La entrevista finalizó con un estrechamiento simbólico de manos y la seguridad que él cancelaría todas las consultas, independientemente de que fuera médico(59).

Tras acatar múltiples tratamientos y comenzando junio de 1939, su cáncer empeora brutalmente: 
se ulcera en la mejilla, emana mal olor, los suplicios somáticos se tornan casi intolerables; la obturación creciente para tragar, la necesidad de tenderse largamente, no impiden su actividad intelectual, continúa finalizando sus libros y atendiendo penosa pero regularmente a sus pacientes. En agosto cancela todas sus citas con enfermos y cierra definitivamente su consulta, se despide de amigos, discípulos y familiares. Su fatiga se agrava en septiembre, las noches se tornan intolerables, da muestras de agradecimiento hacia sus seres amados, el estado caquéctico se acrecienta, no se queja ni irrita ni maldice y, tal como lo decidió al comienzo de su enfermedad, no permite que le prescriban sedantes: "prefiero pensar en medio del tormento a no estar en condiciones de pensar con claridad"(60).

Los informes desde el 21 de septiembre son contradictorios debido a la existencia de diferentes versiones, incluido material clasificado inaccesible aún(61). Freud acude a Schur y le expresa: "usted recuerda nuestra primera conversación en que prometió no dejarme en la estacada cuando llegara el momento. Ahora no es sino tormento y no tiene sentido". Al reasegurarlo Schur, Freud agregó "Ich danke Ihnen, se lo agradezco". Aquí surgen las diferencias sutiles, pero decisivas. Según Jones, "prometió darle una sedación adecuada" y al día siguiente le inyectó $20 \mathrm{mg}$. de morfina(49). Schur publicó que le dio una segunda inyección "después de doce horas"(59). En carta privada a Anna Freud, le explicó que adulteró la versión oficial sobre dosis y número de inyecciones: treinta miligramos en vez de veinte y tres inyecciones en lugar de dos. Schur anota que Freud le dijo después "Sagen Sie es der Anna", "dígale a Anna sobre esto". Pero su reporte no publicado expresa "Besprechen Sie es mit der Anna", que significa "discútalo" con Anna, que coincide mejor con lo que agregó seguidamente: "y si ella piensa que está bien, entonces póngale fin a esto". Siguiendo al inédito, Anna luchó contra la idea, pero finalmente se resignó con la medida de poner término a la agonía de su padre(62).

El proceder ético del morir de Freud se puede entender desde dos niveles. 1] Ética médica. Desde el Juramento en adelante se ha discutido renovadamente sobre el proceso del morir durante la ejecución de un tratamiento médico, teniendo presente el primun non nocere(63). a] El acto emprendido por Schur fue eutanasia, porque tuvo la intención directa de poner fin a la vida a petición expresa, consciente e indudable de Freud, a consecuencia de su estado intolerable de sufrimiento y carencia absoluta de cualquier terapia alternativa eficaz. b] El procedimiento de Schur fue una "sedación terminal", porque su intención era calmar dolores insoportables y ya había agotado todas las terapias que había utilizado anteriormente durante un lapso muy prolongado de tiempo; la causa de la muerte estaba en la incapacidad del cuerpo de Freud para tolerar las dosis que se usan en casos similares para mitigar los sufrimientos, en otros términos, correspondería al principio de doble efecto. El recurrir a esta variedad de muerte-inducida-por-el-médico corresponde a eutanasia-activa-indirecta, y significa que se estaba completa e inequívocamente seguro de que Freud no exigía primariamente la muerte por intermedio de Schur. c] Schur actuó entendiendo la decisión final de su tratamiento médico como una muerte paliada (palliated death). El morir de Freud formó parte del debido cuidado médico (due care), que ininterrumpidamente fue integral, continuado y máxima calidad. Lo central está en el deber profesional primario de Schur, que siempre y en toda ocasión fue entregar la mejor calidad de vida posible, lo que se acredita desde el primer encuentro y no solo en el final de la vida, final que se entiende como prosecución del que invariablemente le había proporcionado - no abandono-(64). 2] La ética de la apropiación. a] Freud se encuentra en la situación inminente de muerte, amenaza que, hasta entonces, había enfrentado y combatido valerosamente hasta extremos casi sobrehumanos, sin abandonar sus convicciones, valores, ideales y metas últimas. b] Había rechazado alternativas no científicas, rebelarse, negarla, huir en el suicidio, sometiéndose responsable y reflexivamente a todas las respuestas científicas durante 16 años. c] Deseaba finalizar el "tormento" (Quälerei) físico y psíquico intolerable, inmanejable, ominoso, sin salida. d] Necesitaba poner término a la falta de sentido en que se había convertido su existencia.

Cabe la pregunta: lo que Freud buscaba, ¿era la muerte misma, o finiquitar el tormento, o especial y profundamente transmutar en sentido pro- 
Los cuestionamientos éticos de Freud: psicoanálisis, existencia y muerte - Gustavo Figueroa

Tabla I: Cronología de la enfermedad del paladar de Freud*

\begin{tabular}{|c|c|c|}
\hline \multirow[t]{2}{*}{1923} & 7 de abril & Félix Deutsch: dos exámenes físicos \\
\hline & 20 de abril & Operación (Dr. Markus Hajek): biopsia y resección paladar \\
\hline \multicolumn{2}{|r|}{$(?)$} & Biopsia: "leucoplasia proliferativa papilar" \\
\hline \multirow{2}{*}{\multicolumn{2}{|c|}{ Mayo (?) }} & Terapia: radium (Dr. Feuchtinger) \\
\hline & & radiación con rayos X (Guido Holzknecht) \\
\hline & Julio & Descanso en Lavarone \\
\hline & 25 de agosto & Examen físico (F. Deutsch) \\
\hline & 26 de agosto & Deutsch informa al "Comité" \\
\hline & ¿7? de septiembre & Viaje a Italia (Roma) \\
\hline & 24 de septiembre & Regreso por hemorragia súbita \\
\hline \multirow{2}{*}{\multicolumn{2}{|c|}{26 de septiembre }} & Se le informa el diagnóstico \\
\hline & & Consulta Dr. Hans Pichler \\
\hline & 4 de octubre & Operación preliminar: vaciamiento ganglionar \\
\hline \multirow{2}{*}{\multicolumn{2}{|c|}{12 de octubre }} & Operación radical: resección maxilar superior derecho \\
\hline & & Biopsia (Oskar Stoerk): probable cáncer (?) \\
\hline & 12 de noviembre & Operación: extirpación restos de tumor \\
\hline & 17 de noviembre & Irradiación (G. Holzknecht) \\
\hline 1936 & 14 de julio & Operación: "carcinoma epitelial” \\
\hline 1939 & 23 de septiembre & Muerte en Londres \\
\hline
\end{tabular}

*Modificado de: Figueroa G. Ética de la revelación del diagnóstico. El caso de Freud. Rev Chil NeuroPsiquiat 1997; 35: 147-160.

pio (eigen) la falta de sentido (Sinnlosigkeit) en que se había trasmutado su vida? El saber de su cáncer lo precipitó en una experiencia perentoria e inédita: "su" muerte como hecho absoluto. No es que Freud no hubiera experimentado muertes importantes, especialmente en su vida reciente: su hija predilecta, Sophie, su nieto amado, Heinerle, su sobrina Cecilie, su amigo Anton von Freund. Empero, ésta era única, por ser in-hóspita (un-heimlich), era un no-estar-en-casa-yamás (Unzuhause), esto es, le abrió dos ámbitos básicos, hasta ese momento ocultos, velados en el tráfago cotidiano: su facticidad y su finitud. Facticidad, porque entendió que sus posibilidades de vida no siempre las puso él, más bien lo opuesto, que siempre había estado ya-arrojado (schon-sein) entre posibilidades y realidades más allá de él mismo y, sin embargo, tenía él que hacerse cargo de todos modos de ellas y, paradojalmente, ahora tenía que tomar él mismo su posibilidad impuesta, inevitable e intransferible, y tornarla en "su" posibilidad: "su" muerte; la paradoja consistía no en "autodeterminarse", sino en "autoelegirse", esto es, no desde la libertad de su voluntad de "determinar" su destino, sino "elegir" sus limitaciones, asumir sus insuficiencias, in-corporar sus carencias, hacer suyas sus negatividades(65). Finitud, porque captó que su ser último consistía en mortalidad, no en que alguna vez se iba a morir, sino que su ser es un ser-referido-a-lamuerte $y$, por tanto, que su muerte es su posibilidad "más propia, intransferible e insuperable", su muerte en tanto posibilidad real y no simple dato ubicado en un futuro incierto(66). En el instante final se le hizo la luz que la muerte, al igual que el vivir, puede ser-impropia o hacersepropia (sich-zueigen-sein) y, por ello, Freud cogió, empuñó, apresó, se adueñó de su muerte; el sin-sentido final era sin-sentido de lo cotidiano pero era el sentido de lo opuesto, de lo primario del hombre, de apropiarse del sin-sentido último y definitivo en que consistía su existencia. La apropiación de Freud, que insinúa en las últimas palabras a Deutsch, es una comprensión radical, que parte desde lo opuesto a lo que vivió cotidiana y diariamente: desde-su-ser-para-el-final (sein-zum-Ende), desde esta posibilidad extrema de ser-ya-nunca-más el ser que puede ser. 


\section{Responsabilidad ética de la existencia de Freud}

Tanto la consistencia ética intrínseca al psicoanálisis como su manera de a-propiarse moralmente de su morir, contienen un presupuesto: desde muy niño, Freud intuyó que su vida era "soportar la carga de la existencia" (Schwere des Daseins)(57). Pero de esta carga inherente a su vida, primaria, original, incomprensible, Freud lentamente empezó a sospechar, presentir, avizorar, que parecía tener un sentido que se le escapaba al ocuparse de sus asuntos cotidianos, cuando entrababa relación con sus pacientes $\mathrm{y}$, también, en la soledad de su intimidad. En otras palabras, no era ni primaria, ni original, ni incomprensible y, aunque sus descubrimientos del Edipo de su autoanálisis tendían a estar sustentando la posible efectividad de un significado más allá del inmediato, Freud necesitó desde la adolescencia — contrariamente - aferrarse a la ciencia y sus resultados empíricos. La ciencia es una concepción o proyecto-previo (Vorentwurf), es constreñirse por anticipado a "una" zona demarcada y determinada de conocimiento; en cuanto preespecifica el saber, capta y percibe como tema posible exclusivamente lo que "su" tipo de figura ha aprobado con anterioridad - lo objetivo $3 / 4$, pero la objetividad no es sino "uno" de los modos posibles de hacerse presente la realidad, pero no el incondicional ni el último(67). Por ello, probablemente Freud no alcanzó a preguntarse por otro tipo de realidad, la de "su" existencia, y si esta está asentada en una ética diferente, anterior, primaria, originaria(68).

La norma moral (Gesetz) no des-cubre ni dejaser (sein-lassen) el fenómeno de lo ético, porque lo entiende de partida, antes de de-velarlo, previo al des-cubrirlo, como un ob-jeto-puesto (ge-setzt) delante por un sub-jeto abstracto -el científico-; en otros términos, lo puesto-delante (Gegen-stand), en-frente, es el ob-jeto (lo que se lanza) para dominarlo y apresarlo, en este sentido, aprehender para unificar el conocimiento y elaborar un mundo coincidente con el de la ciencia. La evidencia de lo percibido es resultado del proceder del científico que re-presenta, porque representar es pro-poner el "sujeto" al "objeto" y consolidarlo haciendo uso del provocar, medir, coger y coaccionar.
Contrariamente al investigar científico, tampoco se trata de un "sujeto" moral, porque nuestra existencia "es" ética y nace del factum que somos ser-en-el-mundo. Ser-en-el-mundo no impone un "sujeto" que está relacionado con un "objeto", como lo entendía el pensamiento antiguo de sustancia (subjectum) o ousia referido a un objectum, en el fondo, entificación de la realidad humana(66). Lo que da a conocer es una unidad compuesta de tres miembros íntimamente interrrelacionados: "existencia", ser siempre proyecto-de-ser lanzado hacia el futuro; "facticidad", estar-arrojado-ya en un mundo que le precede-yse-está-implantado previamente; y "caída" (Verfallenheit), aquello a partir de lo que se entiende a sí inmediata y regularmente, esto es, desde loque-le-ocupa diariamente (pacientes, ambiente social, manejo de útiles, parloteos).

"Soportar la carga de la existencia" significó para Freud una doble condición: a] ser libre para proyectar su ser autoelegiéndose (Selbstwahl) en el tráfago incesante de su existencia habitual diaria; b] no-ser-libre radicalmente, no poder autodeterminarse (Selbstbestimmung), porque jamás forjó su propio fundamento, menos aún fue propietario incondicionado de su ser, la carga de su existencia fue carencia-originaria-de-ser-propio. Opuesto al sentido-de-su-hacer surge el sentidode-su-ser, contrario a suficiencia cotidiana aparece insuficiencia esencial, antitético a riqueza al interior del mundo emerge privación ontológica, enfrentamiento del ejecutar capacidades al noser primario, potencias desarrolladas antagónico a falla intrínseca a la existencia. Entendiendo la carga desde un nivel complementario, es necesario distinguir entre una falta efectuada en su vida y una falta en el fundamento de su ser. Freud comprendió bien y con rigor el "estar-en-deuda" por las faltas cometidas durante su existencia, aunque le fue más oscuro el trasfondo de su falla ontológica: "ser-deudor" original. Mientras la primera, Freud la compensaba reparando el dańo que provocaba acudiendo a una acción, la segunda definía su condición deudora propia última, a la que era posible iluminarla desde su ser último(69).

Freud fue especialmente estricto consigo, lo que se expresó en las llamadas $(R u f)$ permanentes e inflexibles de su conciencia (Gewissen). Pero hay 
que diferenciar entre la llamada de su "mala conciencia", derivada, crítica y censora, amonestaciones estudiadas por Freud con sus pacientes y durante su autoanálisis, y la llamada de su "conciencia existencial u originaria", negatividad del fondo de sí-mismo, oquedad de su fundamento primario, llamada sin palabras audibles que no ordenan ejecutar un acto definido sino conminan a asumir la resolución-anticipadora (Entschlossenheit): rescatarse de su estar-absorbido-por-el-mundo y responsabilizarse hacia un afrontar sin velos ni disfraces su "facticidad" primordial: ser-sí-mismo-en-cuanto-referidoa-la-muerte $(68,70)$. En otras palabras, apertura (Erschlossenheit) para escuchar la llamada sin palabras de la ética originaria hace posible asumir la no-verdad primaria de sí mismo, empezar a comprenderla como posibilidad siempre ejecutable, justi-ficarla, iustum-facere. Entender la ética originaria de Freud permite iluminar desde otro nivel — diferente del de la cotidianidad y del de la ciencia - la ética del psicoanálisis, la apropiación del morir y la responsabilidad ética de la existencia.

\section{Apremios}

1] Freud rehusó ocuparse directamente de la ética, pero su muerte, sus escritos y su existencia apuntan a que lo moral fue un apremio, un dilema, una interpelación que estuvo latente en la base misma de su pensar, y esta interpelación velada apremia a su vez a la bioética a expandir sus preguntas y explorar respuestas creativas.

2] Freud partió del pensamiento científico que, mediante el método operacional, dominador, instrumental, clasificatorio, pone la objetividad como la esencia última de la realidad que consigue

3] La bioética, expresión de este pensar científico, es producto de una subjetividad auto-legisladora, que coloca la voluntad incondicionada fundamento de las normas, valores e ideales, obligatorios en cuanto son lo puesto según su arbitrio legislador.

4] Pero la objetividad no es la única manera de manifestarse la realidad ni el sujeto el modo como se expresa primariamente el ser humano.
Ethos indicaba en sus inicios el habitar o familiaridad primaria del hombre, y este des-cubre su ser como ser-en-el-mundo, por tanto, apertura o morada originaria. Este hogar básico le señala su finitud basal, su ser-referido-a-la-muerte (auténtica e inauténtica) y le indica su facticidad, su abrir posibilidades-elegidas e impuestas-de ser sí-mismo, esto es, lo llama a diferenciar distintas llamadas de su conciencia, su estar-en-deuda de su ser-deudor.

5] Freud contrapuso a la voluntad legisladora, inherente de la bioética moderna operacional y calculadora, la ética de la veracidad dolorosa interminable; antepuso el morir trágico apropiador de su ser mismo frente al sin-sentido último, antes que el drama del morir con sentido médico o legal; se responsabilizó de su existencia, sostenido por su resolución-anticipatoria consciente de ser libre para decidir solo sus preferencias y valores, sin jamás determinar el fundamento de su ser mismo. 


\section{Referencias}

1. Potter VR. Bioethics. Bridge to the future. New Jersey: Yale University Press; 1971.

2. Feito L, Gracia D, Sánchez E, editores. Bioética: el estado de la cuestión. Madrid: Triacastela; 2011.

3. Beauchamp TL, Childress JL. Principles of biomedical ethics. $8^{\text {th }}$ edition. New York: Oxford University Press; 2019.

4. García Gual C, editor. Juramento. En: Tratados hipocráticos. Volumen I. Madrid: Gredos; 1990: 33-42.

5. Reich WT, editor: Encyclopedia of bioethics. 5 Vols. Revised edition. New York: Simon \& Schuster MacMillan; 1995.

6. Jonsen A. The birth of bioethics. New York: Oxford University Press; 1998.

7. MacIntyre A. After virtue. $2^{\text {nd }}$ edition. Notre Dame: University of Notre Dame Press; 1984.

8. Rothman DJ. Strangers at the bedside: A history of how law and bioethics transformed medical decision making. New York: Basic Books; 1991.

9. Figueroa G. ¿̨Por qué bioética hoy? Rev Méd Chile 1995; 123: 777-784.

10. Descartes R. Oeuvres complètes. Paris: Vrin; 2000.

11. Nietzsche F. Die fröhliche Wissenschaft. Werke in drei Bänden II. München: Hanser; 1966: 7-274.

12. Nietzsche F. Morgenröte. Gedanken über die moralischen Vorurteile. Werke in drei Bänden I. München: Hanser; 1966: 10091279 .

13. Figueroa G. Bioética ¿̨la Circe de la medicina? Rev Méd Chile 2001; 129: 209-217.

14. Beca JP, Astete C. Bioética clínica. Santiago de Chile: Mediterráneo; 2012.

15. Heidegger M. Wissenschaft und Besinnung. En: Vortäge und Aufs̈̈tze. 5. Aufl. Pfullingen: Neske; 1967: 41-66.

16. Toulmin S. How medicine saved the life of ethics. Perspectives in biology and medicine (Chicago) 1982; 25: 736-750.

17. Freud S, Pfister O. Briefe 1909-1939. Frankfurt: Fischer; 1963.

18. Young-Bruehl E. Anna Freud. Eine Biographie. 2 Bände. Wien: Wiener Frauenverlag; 1995.

19. Freud S. Briefe an Wilhelm Fließ (1887-1904). Frankfurt: Fischer; 1986.

20. Cortina A. Ética minima. Introducción a la filosofía práctica. 3a edición. Madrid: Tecnos; 1992.

21. Ricoeur P. Psychiatry and moral values. En: Arieti S, editor. American Handbook of Psychiatry. Vol. 1. New York: Basic Books; 1974: 976-990.

22. Freud S. Zur Einleitung der Behandlung. Gesammelte Werke VIII; 1913: 453-478.

23. Freud S. Über Psychoanalyse. Gesammelte Werke VIII; 1910: 1-60.

24. Freud S. Ratschläge für den Arzt bei der psychoanalytischen Behandlung. Gesammelte Werke VIII; 1913: 375-387.

25. Austin JL. How to do things with words. New York: Oxford University Press; 1962.

26. Searle J. Speech acts. An essay in the philosophy of language. London: Cambridge University Press; 1969.

27. López JM. Del hipnotismo a Freud. Orígenes históricos de la psicoterapia. Madrid: Alianza; 2002.

28. Figueroa G. Bioética y psicoterapia. ¿¿Cuáles supuestos morales actúan cuando ejecutamos un acto psicoterapéutico? Rev Méd Chile 2004; 132: 243-252.

29. Laín Entralgo P. La curación por la palabra en la antigüedad clásica. Madrid: Revista de Occidente; 1958.

30. Habermas J. Theorie des kommunikativen Handelns. 2 Bände. Frankfurt: Suhrkamp; 1981.

31. Habermas J. Erkenntnis und Interesse. Mit einem neuen Nachwort. Frankfurt: Suhrkamp; 1973.

32. Foucault M. Technologies of the self. A seminar with Michel Foucault. Amherst: The University of Massachusetts Press; 1988.

33. Foucault M. L’hérmeneutique du sujet. Cours au Collège de France 1981-1982. Paris: Seuil/Gallimard; 2001.

34. Platón. Apología de Sócrates. Diálogos. I. Madrid: Gredos; 1981: 137-185.

35. Foucault M. Histoire de la sexualité. 3. Le souci de soi. Paris: Gallimard; 1984.

36. Nietzsche F. Jenseits von Gut und Böse. Vorspiel einer Philosophie der Zukunft. Werke in drei Bänden II. München: Hanser; 1966: 563-759.

37. Foucault M. Leçons sur la volonté de savoir. Cours au Collelle de France (1970-1971). Paris: Seuil/Gallimard; 2011.

38. Anzieu D. L'auto-analyse de Frend et la découverture de psychanalyse. 2 volumes. Paris: Presses Universitaires de France, 1959.

39. Rudnytsky PL. Freud and Oedipus. New York: Columbia University Press; 1987.

40. Ricoeur P. De l'interprétation. Essai sur Freud. France: Du Seuil; 1965.

41. Krüll M. Freud und sein Vater. Das Entstehung der Psychoanalyse und Freuds ungelöste Vaterbindung. München: Verlag C.H. Beck; 1979. 
Los cuestionamientos éticos de Freud: psicoanálisis, existencia y muerte - Gustavo Figueroa

42. Sófocles. Edipo Rey. Tragedias. Madrid: Gredos; 1981: 301-368.

43. Ricoeur P. Soi-même comme un autre. Paris: Seuil; 1990.

44. Husserl E. Cartesianische Meditationen und Pariser Vorträge. 2. Auflage. Haag: Nijhoff, 1973.

45. Ricoeur P. Le conflit des interprétations. Paris: Seuil; 1969.

46. Freud S. "Psychoanalyse" und "Libidotheorie". Gesammelte Werke XIII; 1923: 209-233.

47. Esquilo. Agamenón. Tragedias. Madrid: Gredos; 2000: 101-171.

48. Deutsche F. Reflections on Freud's one hundred birthday. Psicosom Medicine 1956; 18: 279-283.

49. Jones E. Life and work of Sigmund Freud. 3 Vols. New York: Basic Books; 1957.

50. Grosskurth P. The secret ring. Freud's inner circle and the politics of psychoanalysis. Reading, Massachusets: Addison-Wesley; 1991.

51. Romm S. The unwelcome intruder. Freud's struggle with cancer. New York: Praeger; 1983.

52. Gay P. Freud. A life for our time. New York: WW Norton; 1988.

53. Kollbrunner J. Der kranke Freud. Sttutgart: JG Cotta; 2001.

54. Schavelzon J. Freud. Un paciente con cáncer. Buenos Aires: Paidós; 1983.

55. Roazen P. Freud and his followers. New York: Alfred Knopf; 1971.

56. Figueroa G. Ética de la revelación del diagnóstico. El caso de Freud. Rev Chil Neuro-Psiquiat 1997; 35: 147-160.

57. Freud S. Jenseits des Lustprinzips. Gesammelte Werke 1920; XIII : 1-69.

58. Ricoeur P. The question of proof in Freud's psychoanalytic writings. J Amer Psychoanal Asso 1977; 835-871.

59. Schur M. Freud. Leben und Sterben. Frankfurt: Fischer; 1972.

60. Zweig S. Briefwechsel mit Sigmund Freud, Rainer Maria Rilke und Arthur Schnitzler. Frankfurt: Fischer, 1987.

61. Roudinesco E. Sigmund Freud. En son temps et dans le nôtre. Paris: Seuil; 2014.

62. Jucovy ME. May 19, 1964. The problem of death in Freud's writings and life (Fourteenth Freud Anniversary Lecture). Max Schur, MD. Psychoanal Quart 1965; XXXIV: 144-147.

63. Gracia D. Primum non nocere. El principio de no-maleficiencia como fundamento de la ética médica. Madrid: Instituto de Espańa. Real Academia Nacional de Medicina; 1990.

64. Quill TE. Caring for patients at the end of life. New York: Oxford University Press; 2001.

65. Heidegger M. Ontologie. (Hermeneutik der Faktizität). Gesamtausgabe 63. Frankfurt: Vittorio Klostermann; 1982.

66. Heidegger M. Sein und Zeit. 10. Auflage. Tübingen: Niemeyer; 1963.

67. Heidegger M. Das Ding. En: Vorträge und Aufs̈̈tze. 5. Aufl. Pfullingen: Neske; 1967: 157-175.

68. Cerezo P. De la existencia ética a la ética originaria. En: Cerezo P, Duque F, Leyte A, Martínez F, Peñalver P y Rodríguez R. Heidegger: la voz de tiempos sombríos. Barcelona: Ediciones del Serbal; 1991: 11-79.

69. Figueroa G. La bioética actual: las interrogantes de Heidegger. Rev Méd Chile 2011; 139: 1377-1382.

70. Rodríguez R. La hermenéutica del si mismo en Ser y Tiempo. Del sujeto y la verdad. Madrid: Síntesis; 2005: 61-82.

Recibido: 7 de enero de 2020

Aceptado: 20 de enero de 2020 